Agnes Kukulska-Hulme*

\title{
Reflections on research questions in mobile assisted language learning
}

https://doi.org/10.1515/jccall-2021-2002

Received April 27, 2021; accepted May 30, 2021; published online September 6, 2021

\begin{abstract}
Research questions are central to mobile assisted language learning (MALL) projects and studies, yet they have received little attention to date. Taking research questions as its central focus, this paper offers some reflections on the complexity of the broader field of mobile learning, on different kinds of research, on salient themes and challenges in mobile learning and MALL, and it suggests some research directions for the future. Since MALL research is interdisciplinary, and since research questions are an object of study in other fields of knowledge, the paper refers to sources from multiple disciplines to support a more comprehensive consideration of current and future research questions in MALL. The paper is fundamentally an invitation to a global conversation about research questions in MALL.
\end{abstract}

Keywords: MALL; mobile devices; mobile learning; research agendas; research questions; research topics; smartphones

\section{Introduction}

In this paper I draw on my experience of research, evaluation, project development, as well as supervision and examining of doctoral students' theses over the past two decades, in mobile assisted language learning (MALL) and in mobile learning more broadly. During that time, there have been many opportunities to think about what is worth researching, how the research should be carried out, and what useful knowledge it may produce. Many research projects and studies in MALL are driven by one or more research questions, and that is the aspect I have chosen to focus on in this paper. It seems valuable to reflect on research questions because they underpin the development of any field of research, they may evolve as the field advances, and they set a course for future studies.

\footnotetext{
*Corresponding author: Agnes Kukulska-Hulme, The Open University, Milton Keynes, UK, E-mail: agnes.kukulska-hulme@open.ac.uk

¿ Open Access. (๑) 2021 Agnes Kukulska-Hulme, published by De Gruyter. (co)BY licensed under the Creative Commons Attribution 4.0 International License. 
There is a growing body of publications reviewing the state-of-the-art in mobile learning and mobile assisted language learning, but none of these works looks specifically at what research questions are being addressed overall. This stands in contrast to other fields of knowledge where research questions are frequently debated and priority questions are proposed (Antwis et al., 2017; Freudenberg \& Sharp, 2010; Oldekop et al., 2016; Seddon et al., 2014). In the field of e-learning, Cronje (2020: 13 ) has recognized "a lack of clarity in terms of what is being researched, as well as in how it is being researched" and has proposed a model for developing research questions that are aligned to research aims, using design research as an illustrative example. In language education and applied linguistics, a reference book due to be published in late 2021 (Mohebbi \& Coombe, forthcoming) promises a wealth of suggestions for research questions organized by topic, including some questions for MALL. As yet there appears to be no dedicated published work on existing or future research questions in the field of MALL.

This paper offers some reflections on the nature and focus of research in language learning with mobile technologies and suggests directions for the future. The paper is simultaneously an invitation to a global conversation about research questions in MALL. The conversation might include topics such as: What do researchers, teachers, and others, think about the questions that have guided MALL research to date? Would it be valuable to create a database of research questions that could be analyzed in various ways, and if so, how might they be analyzed? What new research questions, or types of questions, could be suggested for future studies? I hope that readers of this paper will be stimulated to continue this conversation around the world, approaching the issue of research questions from global and local perspectives alike.

\section{The complexity of mobile learning}

Since we shall be considering research questions in MALL, which may be seen as a subfield of mobile learning, a necessary first step is to acknowledge that conceptions of mobile learning are not universal, its definitions have evolved over the years and it has a relationship with the fields of e-learning as well as computer assisted language learning (CALL). Mobile learning may be understood as "an extension of e-learning" (Nami, 2020), or the exact opposite, "not an extension of e-learning” (Hewagamage, Wickramasinghe, \& Jayatilaka, 2012), and "not a new variant of e-learning" (Kukulska-Hulme \& Traxler, 2013). MALL may be considered an extension of CALL (Chang, Warden, Liang, \& Chou, 2018), or the distinction between MALL and CALL may be emphasized (Kukulska-Hulme \& 
Shield, 2008). These different viewpoints exist because mobile devices may be seen as a way to access or interact with materials, resources and communities on digital platforms; or alternatively, the focus may be on what learners can do with personal devices when they are mobile and immersed in diverse physical environments. E-learning is mainly associated with formal education and training, but mobile learning is conducted in both formal and informal settings. Any research questions may thus be influenced by the researcher's choice of perspective and setting.

Different conceptions of mobile learning are likely to have an influence on research questions that guide projects and studies. An explanation of mobile learning offered by the Higher Education association EDUCAUSE (2021) has the traditional classroom as its central reference point:

"Using portable computing devices (such as iPads, laptops, tablet PCs, PDAs, and smart phones) with wireless networks enables mobility and mobile learning, allowing teaching and learning to extend to spaces beyond the traditional classroom. Within the classroom, mobile learning gives instructors and learners increased flexibility and new opportunities for interaction."

The research literature offers many other definitions of mobile learning developed over the last two decades. Crompton (2013) reviewed several definitions and concluded that there were four central constructs: pedagogy, technological devices, context, and social interactions. Together with the editors of the handbook for which she was writing, Crompton added the idea of "content interaction" and suggested that mobile learning should be defined as "learning across multiple contexts, through social and content interactions, using personal electronic devices” (Crompton, 2013, p. 4). While learning 'across multiple contexts' can include the classroom, this definition is more inclusive of diverse scenarios such as informal learning and on-the-job learning where no classrooms are involved. In line with this more inclusive perspective, MALL may be defined as "the use of smartphones and other mobile technologies in language learning, especially in situations where portability and situated learning offer specific advantages" (Kukulska-Hulme, 2018). It is important to note that definitions are frequently surrounded by further elaboration and exemplification that may also be relevant to consider; for example the definition in Kukulska-Hulme (2018) is accompanied by some important remarks: "Increasingly, MALL applications relate language learning to a person's physical context when mobile, primarily to provide access to location-specific language material or to enable learners to capture aspects of language use in situ and share it with others ... Mobile learning is proving its potential to address authentic learner needs at the point at which they arise, and to deliver more flexible models of language learning” (para. 1). 
Definitions of mobile learning partly reflect real-world practices in terms of how researchers or practitioners are using mobile technologies in their projects, but perhaps they also describe what their authors would like mobile learning to be (ideally, or in the future) in terms of where the learning takes place or how it is supported. Some believe there is great value in situated mobile learning at home, at work, outdoors, or across a variety of contexts. Others wish to draw attention to how people may learn by interacting with different types of content (learning materials, artifacts, the natural world) and with other human and artificial beings (teachers, learners, support staff, parents, friends, volunteers, artificial agents) with whom they are in physical contact or connected remotely.

Another distinction worth making is that although pedagogy is identified as one of the central constructs in definitions (Crompton, 2013), mobile learning research is primarily concerned with learners and learning. An alternative term, 'mobile pedagogy' (Kukulska-Hulme, Donohue \& Norris, 2015) was devised to make explicit the teacher's role in the design and promotion of mobile activities that encourage students to engage in language learning as a form of mobile inquiry. For example, students can investigate how language is used in different settings, find ways to practice it in a variety of contexts, and record their experiences for subsequent reflection and discussion. Mobile pedagogy can be viewed as a subset of the broader field of mobile learning which also includes informal learning without teacher involvement.

As pedagogy evolves towards more consideration of how and where learning takes place and how it can be developed beyond the classroom, definitions of mobile learning emphasizing pedagogy or learning design can be enriched by the broader context of learning within a society. Traxler (2009) gave a personal account of the evolution of mobile learning, highlighting numerous definitions and theories, and concluded by suggesting mobile learning is learning that is "most aligned to progressively more mobile societies" (p. 11). At that time, in 2009, it was not a common way of conceptualizing mobile learning and still seems not to have become widespread. What constitutes a 'mobile society' may be understood in various ways, but according to Traxler, Read, Kukulska-Hulme, and Barcena (2019) in the context of mobile learning what matters is that such societies are permeated by personal digital technologies. In mobile societies, there are likely to be evolving conceptions of learning and of how learning can be encouraged and supported through use of personal technologies such as smartphones, tablets, and wearables.

Opinions also differ as to whether the field of mobile learning is young or already in a state of maturity. Kukulska-Hulme, Sharples, Milrad, ArnedilloSánchez, and Vavoula (2011) describe the origins of mobile learning in Europe 
as dating back to small trials and projects in the 1980 and 1990s, with larger projects emerging in the early 2000s. A review of MALL-related literature published between the years 2000 and 2012 (Duman, Orhon, \& Gedik, 2015) noted an increase in publications in the year 2008 and a peak in 2012. According to a subsequent literature review by Aguayo, Cochrane, and Narayan (2017) "mobile learning as a research field has matured since the first attempts at large scale exploratory projects in the early 2000s" (p. 34). Yet some researchers are claiming that the use of mobile wireless technologies is a "recently developed approach to learning in educational environments" (Sarrab, Elbasir, \& Alnaeli, 2016). Others are noting that in their specific contexts or countries mobile learning is new. For example, "Within the Greek formal educational context, mobile learning is in its infancy" (Nikolopoulou, 2018, p. 500); "learning through mobile devices is still in its infancy in Pakistan” (Uppal, Ali, Zahid, \& Basir, 2020, p. 105); and "the field of mobile learning in Tanzania is still in its infancy (Ndume, Songoro, \& Kisanga, 2020). Consequently, research questions that are posed in different contexts may, to some extent, reflect the perceived maturity of mobile learning in those contexts.

Furthermore, since most fields of research are made up of different strands in which new topics and challenges are constantly emerging, it is possible for a field to be mature in some respects and immature in others. Within the field of mobile learning, Buabeng-Andoh (2021) argues that research into the determinants of mobile learning acceptance is in its infancy phase, even though the issue of technology acceptance in education has been studied for a long time. Within MALL, Nami (2020) observes that "there have been relatively few published studies on the use of particular smartphone applications designed for language learning" and suggests that "app-based language learning research is still in its infancy" (p. 85). Therefore, the focus of research questions may be determined by perceptions of aspects of mobile learning that are under-researched, globally or in a particular setting.

The fields of mobile learning and MALL are capacious, ready to embrace a wide range of themes and stages of development. Studies devised by experienced researchers may differ in scope, focus, and methods from those that are devised by researchers who are less experienced, and they may also differ from studies devised by teachers, some of whom have only just begun to research mobile learning as part of their classroom practice. Even if education practitioners are aware that there is an extensive literature on mobile learning, they may be constrained in the extent to which they can access or engage with it, which may mean that they have fewer opportunities to learn from the research questions that others in the field have already explored. 
Research into how people learn with the aid of mobile technologies has changed in some important respects over the past two decades (Crompton \& Traxler, 2019). In early studies, research participants were usually given smartphones and other devices they had never used before and they were asked to try out new applications and sometimes completely new activities. In later studies, a broader range of learners of all ages and in diverse settings have more often used their own technologies and increasingly familiar applications to extend their learning and to focus on specific personal requirements. In the past, research participants may have been largely passive "subjects" who undertook activities requested by researchers (for example, completing a questionnaire, carrying out a task), while more recently, some of them participate more actively, sometimes as co-researchers who may even be involved in the design of the study and learning tasks. In the early days, the bulk of mobile learning research was conducted, published and shared in English; now there are growing numbers of studies available in other languages too. Increasingly, studies investigate real-world contexts; they use a range of research designs and methods; some studies have compared mobile learning with other learning methods or they have compared different designs of mobile learning, but the majority have not been comparative and instead they have focused on mobile learning implementations, investigations, or design improvements (Lai, 2020).

Mobile learning research is shaped by many factors, including, but not limited to: research traditions, competences and beliefs of researchers, available technologies and applications, software development capabilities, resources for data collection and analysis, and expectations regarding the outcomes as well as the impact of the research. These factors are rarely mentioned in overviews of mobile learning research. Burston (2021) has drawn attention to the fact that mobile learning studies are published in a broad range of journals across different disciplines and several domains of professional practice. This suggests that the nature of the research and the methods used are likely to be drawn from, or influenced by, those disciplinary and professional practice values, conventions, and traditions.

\section{The nature of research in mobile learning}

The OECD's Frascati Manual (OECD, 2015) states that research, along with experimental development (collectively known as Research and Development, or $\mathrm{R} \& \mathrm{D})$ comprises "creative and systematic work undertaken in order to increase the stock of knowledge - including knowledge of humankind, culture and society - and to devise new applications of available knowledge" (p. 44). The 
Frascati Manual goes on to identify two types of research, basic and applied: "Basic research is experimental or theoretical work undertaken primarily to acquire new knowledge of the underlying foundation of phenomena and observable facts, without any particular application or use in view.” Applied research is also undertaken to acquire new knowledge, however it is "directed primarily towards a specific practical aim or objective” (p. 45).

Research in MALL is mainly "applied”. Data on aspects such as teachers' or learners' perceptions, attitudes, and practices may be collected, interpreted, and used to inform learning designs and pedagogical interventions that make use of mobile technologies. Empirical studies based in classroom practices are widely used to generate data that supports or refutes an explicit or implicit hypothesis about whether a proposed approach brings about a desired improvement in language learning and associated aspects such as learner motivation. Experimental development of systems and software is also common, especially in projects originating in software engineering and intelligent systems design. Researchers may be steeped in either quantitative or qualitative research traditions and may be unwilling or unable to adopt an alternative approach.

In his commentary on research in educational technology, Selwyn (2010) argued that "academic researchers and writers should give greater acknowledgement to the influences on educational technology above and beyond the context of the individual learner and their immediate learning environment" and that "the use of technology in education needs to be understood in societal terms" (p. 68). If certain technologies are commonly used in daily life, then perceptions of their adoption in education may be influenced by those daily life experiences. Global and local societal challenges may be reflected in mobile learning research projects, for example recent concerns about sustainability ( $\mathrm{Ng}$ \& Cumming, 2016), and if a technology is widely available, it might be a means to satisfy increased demands for education in contemporary times (e.g., Ally \& Tsinakos, 2014; Almarwani, 2011).

In Canada, Pulla (2017) draws attention to the relevance of mobile learning to Indigenous cultures. In contrast to researchers who have been calling for more work on theory in mobile learning (e.g., Traxler \& Koole, 2014), Pulla (2017) argues that "Canadian education researchers need to be re-focusing their efforts away from the theoretical frameworks of education technology and toward the practical application of the lessons learned from the international learning community in the design and delivery of scalable, accessible and inexpensive MLT [mobile learning technology] education applications" (p. 45).

We may ask what is mobile learning research trying to achieve and who will assess whether it is generating useful knowledge. Hulley, Newman, and Cummings (1988) observed that "a good research question should pass the "so 
what" test - getting the answer should contribute usefully to our state of knowledge” (p. 58). For example, answering the research questions makes a positive difference by providing evidence that could lead to an improvement in how something is taught or learned, or who benefits from such an improvement. However, the phrase "our state of knowledge" presupposes that there is a shared pool of knowledge that has been harnessed into an inspectable state or perhaps it is taken on trust. In a world where publications are growing exponentially, researchers may rely on a subset of knowledge within their sphere of interest or they may refer to published, peer-reviewed state-of-the-art reviews. Such reviews, while valuable, are selective in the literature they include and exclude. They may focus on papers published in certain journals only, usually in English (for further discussion of where mobile assisted learning literature is published, see Burston, 2021). While "we" may not all agree on the state of knowledge in MALL or what is important for our context, the "so what" test is still worth applying.

\section{Research topics in mobile learning and MALL}

Fifteen years ago, I took part in a workshop on "Big issues in mobile learning" (Sharples, 2006), in which we explored the meaning and dimensions of the emerging field of mobile learning, and identified several major themes that we (a small group of devoted researchers) considered important to address in mobile learning research:

- How to enhance the learning experience without interfering with it

- Affective factors in learning with mobile devices

- Addressing conflicts between personal informal learning and traditional classroom education

- Appropriate methods for evaluating learning in mobile environments

- How learning activities using mobile technologies should be designed to support innovative educational practices

- How mobile devices could be integrated with broader educational scenarios

While these were identified 'issues' rather than specific research questions, they highlighted several areas of challenge, such as disruption, conflict, integration, informal learning, personalization, and learning design. Each of them seemed to matter. Mobile learning researchers have subsequently worked to some degree on these areas of challenge (e.g., Pollara \& Broussard, 2011; Qing, 2017; Sharples, 2009). As mobile learning has become more widespread over the years, challenges have evolved and other research agendas have been developed (for example, Aguayo et al., 2017; Looi et al., 2010). 
Most recently, researchers have been concerned with adoption of mobile learning (Moya \& Camacho, 2021); implementation (Al-Siyabi \& Dimitriadi, 2020); sustainability (Okai-Ugbaje, Ardzejewska, \& Imran, 2020; Viberg, Andersson, \& Wiklund, 2021); as well as safety, security and privacy (Elaish, Shuib, Ghani, Yadegaridehkordi, \& Alaa, 2017). There have been ongoing attempts to develop an understanding of the processes and products of mobile learning (Bernacki, Greene, \& Crompton, 2020), teaching practices (Romero-Rodríguez, Aznar-Díaz, HinojoLucena, \& Cáceres-Reche, 2020), learning practices (Viberg \& Grönlund, 2017), perceptions (Nikolopoulou, 2020) and challenges in relation to specific subjects or learner groups (e.g., STEM - Hwang, Li, \& Lai, 2020; mobile journalists - Lee, 2021).

Within MALL, alongside abundant research focusing on specific individual language skills or proficiency, recent prominent themes include learner autonomy (Nasr \& Abbas, 2018; Sato, Murase, \& Burden, 2020), use of online sources and apps (Loewen et al., 2019; Zou, Yan, \& Li, 2020) and learning in authentic environments (Shadiev, Hwang, Huang, \& Liu, 2018; Yeung \& Sun, 2021). Hwang and Fu's (2019) review of mobile assisted language learning studies from the period 2007-16 confirms that early studies mainly focused on fostering learners' individual language skills, while later studies have looked at multiple skills in authentic learning environments. Based on a meta-analysis of MALL research and design, Chwo, Marek, and Wu (2018) highlighted "discrepancies between how teachers and instructional designers expected MALL devices to be used and how the students actually used them" (p. 66), which suggests that this could be a topic for further research. They also found that issues of access, motivation, and curriculum often have negative impacts on learning outcomes, which reminds us that research studies that are narrowly focused on mobile technology may overlook the influence of other factors. Commonly investigated topics in MALL studies and gaps in research are also discussed by authors such as Duman et al. (2015) and Burston (2021).

\section{Research questions in mobile assisted language learning}

Many years ago, Dillon (1984) observed that in general "little is known about the kinds of questions that may be posed for research" (p. 361). His review of classifications of question types showed them to be inadequate. Subsequently, White (2013, 2017) has inquired into research questions and has sought to guide researchers in the process of research question development. White (2013: 213) 
explains that the process of formulating, developing, and refining research questions "allows researchers to make connections with existing theories and previous empirical findings and helps avoid unnecessary repetition of, or overlap with, previous work".

Research questions chosen for a study may also reveal something about what researchers consider important to investigate. As noted by Farrow, Iniesto, Weller, and Pitt (2020), "almost all research projects are grounded in trying to answer a question that matters or has consequences" (p.12) and the starting point for a research project "will usually be a research question framed within a particular paradigm” (p. 13) such as positivism or interpretivism. Cronje (2020) refers to the pursuits of knowledge, virtue, value, and power as four underpinning drivers for research. Yet what matters to a research project may also be related to a local context or issue. At times, what researchers have chosen to investigate may be influenced by what their organization, research funding agency, or Ministry of Education considers to be important. Furthermore, discussions with colleagues around the world suggest that our cultures and education systems play a role in shaping conceptions of MALL and what kinds of research studies and questions are valued. Such considerations are rarely articulated in published work.

Research should begin with clear aims and objectives, which will help in the formulation of appropriate research questions. Yet even then, research questions are not easy to get right, and in some research studies they may have to be repeatedly revisited and refined as new data emerge and change our understanding of a phenomenon. Below are several common types of questions that may be encountered in mobile assisted language learning studies. They are formulated here as generic questions. Researchers may wish to consider whether research questions they have used to guide their own studies have been similar to any of these, or whether they are pursuing very different lines of inquiry.

- Does the use of this mobile system lead to improvement in the acquisition of a specific language skill?

This question type focuses on a specific language skill or skills, and it implies that improvement is the desired outcome. The study is probably looking at one specific mobile system. It is focused on a particular technology and a specific skill. It may be trying to measure improvement by using language tests and comparing results.

- What evidence is there that the proposed mobile learning design supports learner collaboration, negotiation, critical thinking, etc.? 
In this type of question, the focus is on a mobile learning design. A learning design could include use of a mobile application as part of a task or a series of tasks. In this research there might be a concern with the various people involved when an application is used - not only the learners, but also those who support the learners, and what resources are available to them. Furthermore, in this question we can detect an interest in some interpersonal and thinking skills that might support language acquisition.

- Does a mobile learning approach have beneficial effects on motivation or affective aspects of learning?

This is another common focus for mobile learning designs and research. The focus here is on learner motivation and affective aspects of learning which may be linked to motivation. The research may be trying to find out whether students are enjoying their learning experience, and whether they are engaged in it, which might have immediate or long-term consequences for their learning. If they are motivated, then perhaps they will sustain their learning for longer and reap the benefits of that.

- How do learners engage in self-organized language learning and what benefits do they derive from it?

Here the learners are using some mobile applications or resources that they found for themselves or that other people have recommended to them. So, the learning is self-motivated and self-organized. The researchers might be interested in the learners' motivation, but also what benefits they derive from the activity. With this type of research question, we are getting closer to the learners' experiences, engaging with the learners, trying to find out what they do and perhaps how it complements their classroom learning.

These "generic" questions could perhaps be mapped on to the four broad question types identified by Cronje (2020) in the context of e-learning research, where the research aims or intent (expressed in research questions) would be to “explain”, “develop”, “describe”, or “explore”. However, in the generic questions outlined here, question types have been combined with discipline-specific areas of common interest and concern, namely language skills, interpersonal skills, personal experience, and learner agency. Sunderland's (2018) introduction to research questions in linguistics categorizes questions as descriptive, explanatory, and evaluative.

Experimental research is perhaps increasingly valued in mobile learning, as researchers conduct studies to show how one way of teaching and learning may be superior to another or produce better outcomes for students. A recent 
experimental study by Hwang and Chang (2021) tries out a new approach to peer-assessment, using a mobile concept mapping system the researchers have developed which should facilitate knowledge construction in elementary science classes. The researchers are interested in the effectiveness of the bi-directional peer-assessment approach supported by their system. The study compares the bidirectional peer-assessment approach with a conventional peer-assessment approach. There are seven research questions, and all of them are in exactly the same form:

RQ1-7: Did the students using the bi-directional peer-assessment approach have ... [better science learning achievement/ better concept mapping scores/ better learning motivation/ better self-efficacy/ better environmental identity/ better critical thinking tendency/better feedback quality/lower cognitive load] ... than those learning with the conventional peer-assessment approach?

These questions enable the researchers to provide answers showing whether the proposed approach resulted in improvements with respect to the aspects they chose to investigate. "Did the students have ..." is a straightforward question type that could also prove useful if other researchers wanted to run studies in a similar area and compare results. It can be used not only in science learning but in language learning too.

In contrast to the experimental approach, Lai and Zheng's (2018) study explored language learners' self-directed use of mobile devices beyond the classroom. They have argued in favor of investigations of learning in informal settings, remarking that "insights into the learning experience in this territory are much needed in order to maximize the educational potentials of mobile learning" (p. 299). The following questions guided their research:

RQ1. What are the different dimensions of learners' self-initiated, self-directed out-of-class language learning with mobile devices?

RQ2. How do language learners utilize different technological tools to construct self-directed out-of-class mobile learning experiences?

Factor analysis enabled the researchers to explain some of the variance in learners' out-of-class mobile learning experience, in particular their activity in terms of personalization, engagement in authentic learning, and using mobile devices to connect with native speakers of the target language and other learners. "What" and "How" in the research questions indicate that the researchers set out to discover more about self-directed mobile language learning and the learners' choice of tools. 
There is room for many different types of studies within mobile assisted language learning, guided by different questions, and more thought should be put into how such studies could complement and build upon each other. In the field of medicine, Perillat and Baigrie (2021) argue that a lack of prioritization among research questions and therapeutics related to the present pandemic was responsible for the duplication of clinical trials and the dispersion of precious resources. Thus sharing research questions could sometimes be a good strategy. It may, however, be constrained by the fact that in some contexts originality of questions may be an implicit requirement, for example in dissertations and theses at doctoral level. It might also be a factor in research that will be judged on its originality for the purposes of quality assessments that evaluate the extent to which an output makes an important and innovative contribution to understanding and knowledge (e.g. REF, 2021).

\section{Conclusions}

This paper has been a means to reflect on challenges and developments in mobile learning and MALL, with special reference to research questions. It brings into focus some of the research questions and question types that are guiding research in mobile assisted language learning, within the broader field of mobile learning. There is scope for a great deal of further investigation of the types of questions that have been pursued to date and what they may reveal about what different stakeholders consider important to investigate in MALL projects and studies in different contexts across the globe.

The field of MALL continues to grow and diversify, which means that an analysis of research questions will need to consider the field in all its complexity. MALL research and development has expanded to include more diverse learners and communities, such as refugees and migrants (Abou-Khalil, Helou, Flanagan, Pinkwart, \& Ogata, 2019; Kukulska-Hulme, 2019), learners with disabilities (Alonso, Read, \& Astrain, 2020), and indigenous youth in cities (Shilling, 2020). In a recent chapter (Kukulska-Hulme, 2021) I highlighted some of the opportunities and issues associated with mobile assisted language learning, based on case studies representing innovative MALL across different sectors of education. Five notable themes running through the case studies were uncovered, suggesting that MALL supports breaking down barriers; unfettered flow of information; frequent interaction and reflection; enjoyment and personal gains; and that it involves a multiplicity of technologies, modalities, and methods. These themes represent key strengths of mobile approaches to teaching and learning that may be developed in environments where teachers and researchers have the ability to try out something 
new. Good research questions could help take these themes forward so that they grow into more substantial bodies of research.

As mobile learning expands beyond smartphones and tablets to other ubiquitous, wearable, and companion-like technologies that are entering our lives, MALL research will continue to thrive. These thoughts are echoed by Shadiev, Hwang, and Huang (2017) when they declare that future studies should investigate the "application of newly learned knowledge to solve daily real-life problems in authentic language learning environments with technology, how to ensure that students are engaged in learning activities, and long-term continuation of such activities.” (p. 290). For future studies, they suggest considering more advanced intelligent technologies for supporting language learning in authentic environments: "For example, wearable devices, such as clothing and accessories, incorporating computer and advanced electronic technologies. Some recent popular examples are optical head-mounted displays, smartwatches or smart bracelets" (p. 292). New research questions will need to accompany these developments, some based on previous questions and others that we have not thought of yet.

\section{References}

Abou-Khalil, V., Helou, S., Flanagan, B., Pinkwart, N., \& Ogata, H. (2019). Language learning tool for refugees: Identifying the language learning needs of Syrian refugees through participatory design. Languages, 4(3), 71.

Aguayo, C., Cochrane, T., \& Narayan, V. (2017). Key themes in mobile learning: Prospects for learner-generated learning through AR and VR. Australasian Journal of Educational Technology, 33(6), 27-40.

Al-Siyabi, M. A., \& Dimitriadi, Y. (2020). Opportunities and challenges of mobile learning implementation in schools in Oman. International Journal of Mobile and Blended Learning, 12(3), 32-48.

Ally, M., \& Tsinakos, A. (2014). Increasing access through mobile learning. Vancouver: Commonwealth of Learning and Athabasca University.

Almarwani, M. (2011). ML for EFL: Rationale for mobile learning. The 4th edition "ICT for Language Learning” Conference. ICT4LL, Pixel. Retrieved from https://conference.pixel-online.net/ conferences/ICT4LL2011/common/download/Paper_pdf/IBL52-365-FP-AlmarwaniICT4LL2011.pdf.

Alonso, C., Read, T., \& Astrain, J. J. (2020). Helping people with language learning disabilities using native mobile voice recognition-Exploring its limits and advantages. International Journal of Information and Education Technology, 10(8), 590-596.

Antwis, R. E., Griffiths, S. M., Harrison, X. A., Aranega-Bou, P., Arce, A., Bettridge, A. S., \& Sutherland, W. J. (2017). Fifty important research questions in microbial ecology. FEMS Microbiology Ecology, 93(5), fix044.

Bernacki, M. L., Greene, J. A., \& Crompton, H. (2020). Mobile technology, learning, and achievement: Advances in understanding and measuring the role of mobile technology in education. Contemporary Educational Psychology, 60, 101827. 
Buabeng-Andoh, C. (2021). Exploring University students' intention to use mobile learning: A research model approach. Education and Information Technologies, 26(1), 241-256.

Burston, J. (2021). Unreported MALL studies: What difference do they make to published experimental MALL research results? In V. Morgana, \& A. Kukulska-Hulme (Eds.), Mobile assisted language learning across educational contexts. Routledge Focus on Applied Linguistics. Abingdon: Routledge.

Chang, C. C., Warden, C. A., Liang, C., \& Chou, P. N. (2018). Performance, cognitive load, and behaviour of technolog-assisted English listening learning: From CALL to MALL. Journal of Computer Assisted Learning, 34(2), 105-114.

Chwo, G. S. M., Marek, M. W., \& Wu, W. C. V. (2018). Meta-analysis of MALL research and design. System, 74, 62-72.

Crompton, H. (2013). A historical overview of m-learning: Toward learner-centered education. In Z. L. Berge, \& L. Y. Muilenburg (Eds.), Handbook of mobile learning (pp. 3-14). London: Routledge.

Crompton, H., \& Traxler, J. (2019). Learning with mobile devices. In M. Khosrow-Pour (Eds.), Advanced methodologies and technologies in modern education delivery (pp. 793-808). IGI Global.

Cronje, J. C. (2020). Designing questions for research design and design research in e learning. Electronic Journal of e-Learning, 18(1), 13-24.

Dillon, J. T. (1984). The classification of research questions. Review of Educational Research, 54(3), 327-361.

Duman, G., Orhon, G., \& Gedik, N. (2015). Research trends in mobile assisted language learning from 2000 to 2012. ReCALL: The Journal of EUROCALL, 27(2), 197.

EDUCAUSE. (2021). Mobile learning. Retrieved from https://library.educause.edu/topics/ teaching-and-learning/mobile-learning.

Elaish, M. M., Shuib, L., Ghani, N. A., Yadegaridehkordi, E., \& Alaa, M. (2017). Mobile learning for English language acquisition: Taxonomy, challenges, and recommendations. IEEE Access, 5, 19033-19047.

Farrow, R., Iniesto, F., Weller, M., \& Pitt, R. (2020). GO-GN research methods handbook. Milton Keynes: Global OER Gradate Network.

Freudenberg, S., \& Sharp, H. (2010). The top 10 burning research questions from practitioners. leee Software, 27(5), 8-9.

Hewagamage, K. P., Wickramasinghe, W. M. A. S. B., \& Jayatilaka, A. D. S. (2012). “M-Learning not an extension of e-learning": Based on a case study of Moodle VLE. International Journal of Mobile and Blended Learning, 4(4), 21-33.

Hulley, S. B., Cummings, S. R., \& Browner, W. (1988). Getting started: The anatomy and physiology of research. In S. B. Hulley, \& S. R. Cummings (Eds.), Designing clinical research. Baltimore: Williams \& Wilkins.

Hwang, G. J., \& Chang, S. C. (2021). Facilitating knowledge construction in mobile learning contexts: A bi-directional peer-assessment approach. British Journal of Educational Technology, 52(1), 337-357.

Hwang, G. J., \& Fu, Q. K. (2019). Trends in the research design and application of mobile language learning: A review of 2007-2016 publications in selected SSCI journals. Interactive Learning Environments, 27(4), 567-581.

Hwang, G. J., Li, K. C., \& Lai, C. L. (2020). Trends and strategies for conducting effective STEM research and applications: A mobile and ubiquitous learning perspective. International Journal of Mobile Learning and Organisation, 14(2), 161-183. 
Kukulska-Hulme, A. (2018). Mobile-assisted language learning [Revised and updated version]. In C. A. Chapelle (Eds.), The concise encyclopedia of applied linguistics. New York: Wiley. Retrieved from http://oro.open.ac.uk/57023/.

Kukulska-Hulme, A. (2019). Mobile language learning innovation inspired by migrants. Journal of Learning for Development, 6(2), 116-129.

Kukulska-Hulme, A. (2021). Conclusions: A lifelong perspective on mobile language learning. In V. Morgana, \& A. Kukulska-Hulme (Eds.), Mobile assisted language learning across educational contexts. Routledge focus on applied linguistics (pp. 122-133). Abingdon: Routledge.

Kukulska-Hulme, A., \& Shield, L. (2008). An overview of mobile assisted language learning: From content delivery to supported collaboration and interaction. ReCALL, 20(3), 271-289.

Kukulska-Hulme, A., \& Traxler, J. (2013). Design principles for mobile learning. In H. Beetham, \& R. Sharpe (Eds.), Rethinking pedagogy for a digital age: Designing for 21st century learning (2nd ed., pp. 244-257). Abingdon: Routledge.

Kukulska-Hulme, A., Sharples, M., Milrad, M., Arnedillo-Sánchez, I., \& Vavoula, G. (2011). The genesis and development of mobile learning in Europe. In D. Parsons (Eds.), Combining e-learning and m-learning: New applications of blended educational resources (pp. 151-177). Hershey, PA: Information Science Reference (an imprint of IGI Global).

Kukulska-Hulme, A., Norris, L., \& Donohue, J. (2015). Mobile pedagogy for English language teaching: A guide for teachers. The British Council. Retrieved from http://oro.open.ac.uk/ 43605/.

Lai, C. L. (2020). Trends of mobile learning: A review of the top 100 highly cited papers. British Journal of Educational Technology, 51(3), 721-742.

Lai, C., \& Zheng, D. (2018). Self-directed use of mobile devices for language learning beyond the classroom. ReCALL, 30(3), 299-318.

Lee, Y. M. (2021). Digital skills of mobile journalists: Exploring learning needs and learner experiences of just-in-time learning with smartphones. Journalism and Mass Communication Educator. Online First. https://doi.org/10.1177/10776958211001692.

Loewen, S., Crowther, D., Isbell, D. R., Kim, K. M., Maloney, J., Miller, Z. F., \& Rawal, H. (2019). Mobile-assisted language learning: A Duolingo case study. ReCALL: The Journal of EUROCALL, 31(3), 293-311.

Looi, C. K., Seow, P., Zhang, B., So, H. J., Chen, W., \& Wong, L. H. (2010). Leveraging mobile technology for sustainable seamless learning: A research agenda. British Journal of Educational Technology, 41(2), 154-169.

Mohebbi, H., \& Coombe, C. (Eds.) (forthcoming). Research questions in language education and applied linguistics: $A$ reference guide. Berlin: Springer.

Moya, S., \& Camacho, M. (2021). Identifying the key success factors for the adoption of mobile learning. Education and Information Technologies, 26, 3917-3945.

Nami, F. (2020). Educational smartphone apps for language learning in higher education: Students' choices and perceptions. Australasian Journal of Educational Technology, 36(4), 82-95.

Nasr, H. A., \& Abbas, A. A. (2018). Impact of mobile assisted language learning on learner autonomy in EFL reading context. Journal of Language and Education, 4(2), 48-58.

Ndume, V. A., Songoro, M., \& Kisanga, D. H. (2020). Enriching performance of mathematics in Secondary Schools Using Mobile Learning. International Journal of Education and Development using Information and Communication Technology, 16(2), 223-241. 
Ng, W., \& Cumming, T. M. (Eds.) (2015). Sustaining mobile learning: Theory, research and practice. Abingdon: Routledge.

Nikolopoulou, K. (2018). Mobile learning usage and acceptance: Perceptions of secondary school students. Journal of Computers in Education, 5(4), 499-519.

Nikolopoulou, K. (2020). Secondary education teachers' perceptions of mobile phone and tablet use in classrooms: Benefits, constraints and concerns. Journal of Computers in Education, 7(2), 257-275.

OECD. (2015). Frascati Manual 2015: Guidelines for collecting and reporting data on research and experimental development. Paris: Organisation for Economic Co-operation and Development. OECD Publishing. Retrieved from http://www.oecd.org/sti/frascati-manual2015-9789264239012-en.htm.

Okai-Ugbaje, S., Ardzejewska, K., \& Imran, A. (2020). Readiness, roles, and responsibilities of stakeholders for sustainable mobile learning adoption in higher education. Education Sciences, 10(3), 49.

Oldekop, J. A., Fontana, L. B., Grugel, J., Roughton, N., Adu-Ampong, E. A., Bird, G. K., \& Sutherland, W. J. (2016). 100 key research questions for the post-2015 development agenda. Development Policy Review, 34(1), 55-82.

Perillat, L., \& Baigrie, B. S. (2021). COVID-19 and the generation of novel scientific knowledge: Research questions and study designs. Journal of Evaluation in Clinical Practice, 27(3), 694-707.

Pollara, P., \& Broussard, K. K. (2011). Student perceptions of mobile learning: A review of current research. Proceedings of society for information technology \& teacher education international conference 2011 (pp. 1643-1650). Chesapeake, VA: AACE.

Pulla, S. (2017). Mobile learning and indigenous education in Canada: A synthesis of new ways of learning. International Journal of Mobile and Blended Learning, 9(2), 39-60.

Qing, M. (2017). A multi-case study of university students' language-learning experience mediated by mobile technologies: A socio-cultural perspective. Computer Assisted Language Learning, 30(3-4), 183-203.

REF. (2021). Research excellence framework. UK Higher Education. Retrieved from https://www. ref.ac.uk/.

Romero-Rodríguez, J. M., Aznar-Díaz, I., Hinojo-Lucena, F. J., \& Cáceres-Reche, M. P. (2020). Models of good teaching practices for mobile learning in higher education. Palgrave Communications, 6(1), 1-7.

Sarrab, M., Elbasir, M., \& Alnaeli, S. (2016). Towards a quality model of technical aspects for mobile learning services: An empirical investigation. Computers in Human Behavior, 55, $100-112$.

Sato, T., Murase, F., \& Burden, T. (2020). An empirical study on vocabulary recall and learner autonomy through mobile-assisted language learning in blended learning settings. Calico Journal, 37(3), 254-276.

Seddon, A. W. R., Mackay, A. W., Baker, A. G., Birks, H. J. B., Breman, E., Buck, C. E, ... McGlone, M. (2014). Looking forward through the past: Identification of 50 priority research questions in palaeoecology. Journal of Ecology, 102(1), 256-267.

Selwyn, N. (2010). Looking beyond learning: Notes towards the critical study of educational technology. Journal of Computer Assisted Learning, 26(1), 65-73. 
Shadiev, R., Hwang, W. Y., \& Huang, Y. M. (2017). Review of research on mobile language learning in authentic environments. Computer Assisted Language Learning, 30(3-4), 284-303.

Shadiev, R., Hwang, W. Y., Huang, Y. M., \& Liu, T. Y. (2018). Facilitating application of language skills in authentic environments with a mobile learning system. Journal of Computer Assisted Learning, 34(1), 42-52.

Sharples, M. (Ed.) (2006). Big issues in mobile learning. Report of a workshop by the Kaleidoscope Network of Excellence Mobile Learning Initiative. University of Nottingham.

Sharples, M. (2009). Methods for evaluating mobile learning. In G. N. Vavoula, N. Pachler, \& A. Kukulska-Hulme (Eds.), Researching mobile learning: Frameworks, tools and research designs (pp. 17-39). Oxford: Peter Lang Publishing Group.

Shilling, A. J. (2020). Exploring the use of mobile language learning technology as a means for urban Indigenous youth to connect to identity and culture [Doctoral dissertation]. Vancouver: University of British Columbia. Retrieved from https://open.library.ubc.ca/cIRcle/ collections/ubctheses/24/items/1.0391007.

Sunderland, J. (2018). Research questions in linguistics. In L. Litosseliti (Eds.), Research methods in linguistics (2nd ed., pp. 9-28). London: Bloomsbury Publishing.

Traxler, J. (2009). The evolution of mobile learning. In R. Guy (Eds.), The evolution of mobile teaching and learning (pp. 1-14). Santa Rosa, California: Informing Science Press.

Traxler, J., \& Koole, M. (2014). The theory paper: What is the future of mobile learning? International Association for the Development of the Information Society.

Traxler, J., Read, T., Kukulska-Hulme, A., \& Barcena, E. (2019). Paradoxical paradigm proposals Learning languages in mobile societies. Argentinian Journal of Applied Linguistics, 7(2), 89-109.

Uppal, M. A., Ali, S., Zahid, Z., \& Basir, M. (2020). Factors determining student's perception towards mobile learning: An empirical study of Pakistan's higher education. Pakistan Journal of Distance and Online Learning, 5(2), 101-121.

Viberg, O., Andersson, A., \& Wiklund, M. (2021). Designing for sustainable mobile learning - Reevaluating the concepts "formal" and "informal". Interactive Learning Environments, 29(1), 130-141.

Viberg, O., \& Grönlund, Å. (2017). Understanding students' learning practices: Challenges for design and integration of mobile technology into distance education. Learning, Media and Technology, 42(3), 357-377.

White, P. (2013). Who's afraid of research questions? The neglect of research questions in the methods literature and a call for question-led methods teaching. International Journal of Research and Method in Education, 36(3), 213-227.

White, P. (2017). Developing research questions. London: Macmillan International Higher Education.

Yeung, W. K., \& Sun, D. (2021). An exploration of inquiry-based authentic learning enabled by mobile technology for primary science. International Journal of Mobile Learning and Organisation, 15(1), 1-28.

Zou, B., Yan, X., \& Li, H. (2020). Students' perspectives on using online sources and apps for EFL learning in the mobile-assisted language learning context. Language learning and literacy: Breakthroughs in research and practice (pp. 515-531). Hershey, PA: IGI Global. 


\section{Bionote}

\section{Agnes Kukulska-Hulme}

The Open University, Milton Keynes, UK

agnes.kukulska-hulme@open.ac.uk

Agnes Kukulska-Hulme is Professor of Learning Technology and Communication in the Institute of Educational Technology at The Open University, UK, where she leads the Future Learning Research and Innovation Programme. Her work encompasses online distance education, mobile learning and language learning. Professor Kukulska-Hulme is on the Editorial Boards of ReCALL, RPTEL, International Journal of Mobile and Blended Learning, and Waikato Journal of Education.

Her publications include over 200 articles, papers and books, and she has also authored policy and practice reports for UNESCO, British Council, the Commonwealth of Learning, the International Research Foundation for English Language Education and Cambridge University Press. She has been an invited speaker at over 100 international conferences and events. 